\title{
Keberangkatan Jaka Sembung Dalam Komik Pendekar Gunung Sembung (1969): Kajian Monomyth
}

\author{
Restu Ismoyo Aji \\ Pengajar \\ Program Studi Desain Komunikasi Visual \\ Fakultas Arsitektur dan Desain \\ Universitas Pembangunan Nasional "Veteran" Jawa Timur \\ restu.ismoyo.dkv@upnjatim.ac.id
}

\begin{abstract}
This study aims to find out how far The Departure pattern of Joseph Campbell's Monomyth or Hero's Journey is present in the narration of Jaka Sembung's character in the silat (martial arts) comic Pendekar Gunung Sembung by Djair (1969), and whether the modern characteristics of comics play a role in this mythical pattern. Departure in monomyth is very important. It determines the motivations and goals of the characters in the comic as a whole. Monomyth analysis is applied flexibly to verbal aspects combined with comic visual aspects. The results of the study revealed that there were five sub-stages of The Departure in Jaka Sembung's journey with several modern adjustments.
\end{abstract}

Keywords: Djair, Jaka Sembung, Joseph Campbel, martial arts comic, monomyth.

\section{PEMBAHASAN}

Sebagai produk yang bertujuan komersial tetapi kerap dituduh menyebarkan kebodohan, komik diizinkan tetap hidup asalkan memuat pesan moral dan kebudayaan nasional (Bonneff, 2008). Gelombang komik silat yang dimulai oleh Ganes TH lewat Si Buta dari Goa Hantu bukan kebetulan muncul bersamaan dengan upaya disatukannya seluruh aliran dan perguruan pencak silat di Indonesia dalam usaha menjadikannya sebagai bagian identitas nasional, sebuah identifikasi imajinatif negarabangsa yang direproduksi melalui simbol dan diskursus (Barker, 2013:207). Unik tentu saja, ketika komik yang serba dicurigai malah menjelma semacam corong kebudayaan nasional.

Membicarakan komik silat, akan sulit membantah bahwa Jaka Sembung adalah salah satu tokoh rekaan komik silat Indonesia yang tampil amat manusiawi sekaligus memikat dengan latar hidup yang lengkap. Tidak seperti pendekar lain yang sepanjang hidup hanya mengembara, Jaka Sembung menetap, menikah, dan bertani layaknya penduduk desa pada umumnya. Selain taat melaksanakan perintah agama Islam, Jaka Sembung juga menebar semangat nasionalisme untuk melawan pihak Kompeni Belanda (VOC) dengan membangun benteng pertahanan di desa Kandanghaur (sebuah wilayah yang sungguh-sungguh ada). Sehingga wajar saja jika ada sebagian kalangan yang menganggap bahwa Jaka Sembung adalah tokoh sejarah, sesuatu yang disayangkan oleh Djair sendiri (Kurnia, 2017:84-110).

Dalam komik Pendekar Gunung Sembung (selanjutnya disingkat $P G S$ ) karya Djair (1969), Parmin melanjutkan pengembaraannya setelah berangkat dari Pantai Eretan, mengemban tugas dari gurunya 
untuk menggabungkan para pendekar di Selatan demi menyingkirkan penjajah Belanda. Dia mendaki gunung Cereme (ditulis Ciremai dalam komik). Mencapai lerengnya dia diangkat sebagai murid oleh seorang kakek misterius. Menjelang puncak gunung dia bukan saja bertemu dengan ayah kandung dan dua saudara kandungnya, namun mengetahui pula asal-usulnya yang ternyata keturunan bangsawan Keraton. Parmin lalu berpisah dengan keluarganya, menolong penduduk desa dari gerombolan perampok Lalawa Hideung dan juga dari Kyai Subeni yang gemar berbuat cabul. Setelah tugas dari gurunya dirasa rampung, dia mengambil jalur memutar, pulang untuk menemui gurunya, dan kembali ke kekasihnya untuk menikah.

Jalinan narasi yang sedikit berbeda ini tidak lantas membuat Jaka Sembung lepas dari imaji kependekaran yang mana mengambil jarak walau tidak total dari lingkup hero universal. Istilah "hero" digunakan dalam tulisan ini demi menghindari kerancuan dengan istilah "pahlawan" yang berkonotasi pada gelar yang diberikan oleh Pemerintah kepada orang yang dianggap berjasa bagi negara. Pendekar kebanyakan berwajah rupawan dengan fisik yang sempurna dan digilai lawan jenisnya. Pendekar dikagumi dari fungsi moralnya sebagai penumpas kejahatan dan pembela kebenaran. Menguasai ilmu silat dan memiliki senjata andalan. Pendekar melakukan sebuah pengembaraan dari satu tempat ke tempat lain dengan suatu tugas khusus.

Hal ini disebut sebagai model naratif hero. Manusia mempunyai model mental atau imaji yang darinya manusia mendasarkan pengharapan yang kemudian menuntun persepsi dan memorinya. Khusus untuk hero dan penjahat, pola-polanya bersifat general (Allison dan Goethals, 2011:71-72). Pola-pola ini lebih berdasar pada pengalaman kolektif manusia dan imaji-imaji bawah sadar yang diwariskan dari evolusi pikiran manusia. Oleh Carl Jung imaji-imaji bawah sadar yang laten ini disebut arketipe. Arketipe berada di bawah sadar bukan karena ditekan tapi karena tidak dibawa ke kesadaran. Gagasan-gagasan tersebut mewujud dalam simbol-simbol modern dan karakter fiksi. Terbukti melalui pendekatan semiotika, figur superhero modern seperti Superman sebenarnya mengulangi tradisi hero mitis yang didaur ulang dan didandani dengan kemasan kontemporer (Danesi, 2002:47). Siapapun tokohnya hanya akan ada sedikit perbedaan dalam morfologi petualangannya.

Salah satu teori yang membicarakan polapola mitis ini adalah "Monomyth" atau Hero's Journey (perjalanan seorang hero) dari buku The Hero with a Thousand Faces (Campbell, 2004) yang terbit pertama kali tahun 1949. Bahwa semua cerita di dunia punya kerangka dan detail yang sama. Cerita dimulai dari panggilan kepada si hero untuk bertualang ketika muncul suatu ancaman. Melalui penaklukan ancaman itu, sang hero menyadari potensi dan perannya. Pada akhirnya dia kembali ke tempat dia berasal membawa hadiah besar yang diperolehnya selama petualangan untuk dibagikan kepada orang-orang yang dia tinggalkan.

Kata mitos berasal dari bahasa Yunani yang artinya kata, pidato, kisah para dewa. Mitos adalah naratif di mana karakternya adalah dewa, hero, dan makhluk mistikal, dengan alur mengenai asal usul segala sesuatu atau peristiwa metafisik, dan berlatar dunia metafisik yang disandingkan dengan dunia 
nyata. Pada tahap awal budaya manusia, mitos berfungsi sebagai 'teori naratif tentang dunia. Sehingga setiap budaya menciptakan mitos untuk menjelaskan asal-usul mereka.

Jalur umum lingkaran mitologi ini berupa penegasan formula yang direpresentasikan dalam ritus perjalanan: Keterpisahan (Keberangkatan), Inisiasi, dan Kepulangan Kembali, yang dipinjam Campbell (2004:28) dari Finnegans Wake karya James Joyce.

"A hero ventures forth from the world of common day into a region of supernatural wonder: fabulous forces are there encountered, and a decisive victory is won: the hero comes back from this mysterious adventure with the power to bestow boons on his fellow man." (Seorang hero bertualang dari dunia biasa ke wilayah supranatural: kekuatan hebat dihadapi, dan kemenangan penting diraih: si hero kembali dari petualangan misterius ini dengan kekuasaan untuk membagi anugerah ini kepada sesama manusia).

Perjalanan hero tersebut dapat diringkas sebagai berikut: Hero mitis, berangkat dari kediamannya, memasuki ambang petualangan. Di sana dia bertemu dengan penjaganya. Si hero lalu mengalahkan atau mendamaikan semua kekuatan yang menghalanginya, atau dibunuh oleh musuh dan mengalami kematian. Si hero melanglang di dunia asing, yang memberinya ujian, dan sebagian lagi menolongnya. Ketika dia tiba di titik nadir, dia mengalami cobaan berat dan meraih ganjarannya. Kemenangannya direpresentasikan oleh penyatuan seksual dengan Dewi-Ibu (pernikahan suci), pengakuannya atas Pencipta-Ayah (penebusan ayah), keilahiaanya (apotheosis), atau jika kekuatan itu masih menghalangi, pencuriannya terhadap anugerah yang dicarinya; secara intrinsik dia adalah perluasan kesadaran (pencerahan, transfigurasi, kebebasan). Ketika kekuatan itu sudah memberkahi hero, dia kini di bawah perlindungannya; jika tidak, dia melarikan diri dan dikejar (penerbangan ajaib). Di ambang kepulangan, kekuatan transendental harus ditinggal; si hero bangkit dari ketakutannya (kebangkitan). Anugerah yang dibawanya memulihkan dunia (hadiah/elixir) (Campbell,2004:227-228).

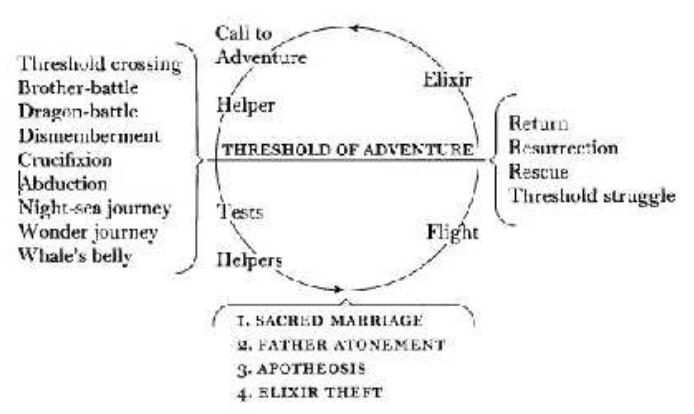

Gambar 1 diagram Perjalanan Hero Sumber: Campbell, 2004:227

Keterpisahan atau Keberangkatan (Departure) secara detail terdiri dari: (1)"Panggilan untuk Bertualang" (The Call to Adventure) atau hadirnya tugas untuk sang hero; (2)"Penolakan atas Panggilan" (Refusal of The Call); (3)"Bantuan Supranatural" (Supernatural Aid), bantuan yang tidak terduga yang datang kepada mereka yang sudah menjalani petualangannya; (4)"Melewati Ambang Pintu" (The Crossing of The First Threshold); dan (5)"Perut Ikan Paus" (Belly of The Whale) atau berjalan menembus malam.

Dari pemaparan di atas diajukan suatu pertanyaan, seberapa jauh pola Keberangkatan (Departure) Monomyth hadir pada narasi tokoh Jaka Sembung dalam komik silat PGS (1969), 
serta adakah karakter modern komik berperan terhadap pola tersebut.

Penelitian ini adalah penelitian kualitatif yang berfokus pada aspek verbal komik PGS (Djair, 1969), yang membuat aspek visual dari komik ini menjadi data sekunder. Ciri komik terbitan 1950-an hingga 1970-an yang didominasi kategori pertama dalam pembagian komposisi kata dan gambar kata-spesifik menurut McCloud (1993:53), menunjukkan bahwa kata-kata dalam komik sudah menjelaskan segala yang perlu diketahui pembaca, di mana gambar hanya mengilustrasikan satu aspek adegan.

Tahapan analisis dimulai dari pembacaan terhadap teks komik secara keseluruhan. Kemudian naratif Jaka Sembung dalam PGS (Djair, 1969) dianalisis dengan mengklasifikasikannya ke dalam tahapan Monomyth yang terdiri dari tiga bagian besar: Keberangkatan (Departure), Inisiasi (Initiation), dan Kepulangan Kembali (Return). Bagi Campbell, perjalanan hero adalah mengenai pergi keluar dari, dan melampaui lingkup komunitasnya (Rensma, 2009:109). Artinya fase Keberangkatan memegang posisi posisinya yang begitu penting bagi keseluruhan naratif bagi Sang Hero, Jaka Sembung sebagai pendekar. Keberangkatanlah yang menentukan motivasi dan tujuan petualangan seorang hero yang nantinya menentukan fase Inisiasi dan Kepulangan Kembali

\section{PEMBAHASAN}

Adalah lumrah bagi seorang komikus untuk memanjangkan cerita dengan cara menceritakan tokoh-tokoh sampingan atau pendukung. Parmin tidak selalu menjadi fokus utama dalam setiap judul serialnya, melainkan malah teman, saudara, dan istrinya. Tidak terkecuali dalam komik PGS (Djair, 1969) di mana tokoh-tokoh yang sudah pernah muncul dari judul-judul sebelumnya hadir kembali, sembari memperkenalkan tokoh-tokoh baru. Begitu pula musuh-musuh yang sumbangsihnya terhadap alur cerita sebenarnya kecil namun berfungsi bukan hanya untuk menambah ketegangan cerita tetapi ikut membangun pola mitis kependekaran Jaka Sembung.

Sebelumnya akan dipaparkan ringkasan cerita komik PGS (Djair, 1969) yang berkaitan dengan fase Keberangkatan. Parmin yang kini bergelar Jaka Sembung mendaki gunung Ciremai sesuai perintah gurunya. Di sebuah petilasan Wali Songo dia diserang Dewa Suci Penyebar Bala yang masih menaruh dendam kepadanya setelah kalah dalam pertarungan terdahulu. Bentrok singkat membuat Parmin terlempar dari tebing. Beruntung sebuah pohon mencegahnya terhempas ke dasar jurang. Ketika halimun dingin menusuk tulang menyelimuti lereng gunung, Parmin jatuh pingsan. Seorang tua berjuluk Begawan Sokalima menolongnya dan mengangkatnya menjadi murid. Darinya dia mewarisi Ilmu Tongkat dan menerima sebilah tongkat besi berani. Parmin kemudian melanjutkan perjalanan.

Menjelang puncak gunung, dia bertemu kembali dengan ayah kandungnya sejak diasuh Ki Sapu Angin sewaktu masih kanak-kanak dan dua saudara kandungnya untuk pertama kali. Dari ayahnya, Sutawinata, Parmin mengetahui bahwa dia adalah keturunan bangsawan Keraton Kasultanan Kanoman Cirebon. Ayahnya diusir Sultan setelah nasehatnya untuk melawan Kompeni bertentangan dengan kemauan Sultan yang ingin berkompromi dengan Belanda. 
Ketika menuruni gunung dia bertemu seekor burung beo ajaib yang dapat bicara dan memahami perkataan manusia. Setelah terjadi tanya jawab mengenai agama, Tuhan, dan kitab suci, Si Beo mengabdikan diri kepada Parmin dan beberapa kali menolongnya dari kepungan musuh. Seperti saat dia melawan gerombolan perampok Lalawa Hideung yang mengganggu penduduk desa Kalimanggis.

1. Panggilan untuk Bertualang (The Call to Adventure)

Tahapan pertama dari perjalanan seorang hero adalah "Panggilan untuk Bertualang." Petualangan Jaka Sembung dalam seluruh perjalanannya di komik PGS (Djair, 1969) dapat dipisahkan secara spesifik menjadi tiga. Pertama, untuk menolong sesamanya dari kesusahan, memusnahkan kejahatan, mengamalkan ilmu silatnya. Tugas ini sudah menjadi tugas dari pendekar dan hero manapun. Kedua, bergabung dengan atau menyatukan para pendekar di Selatan untuk menyingkirkan Kompeni Belanda, dan Ketiga, mencari jati dirinya. Tugas yang terakhir adalah tugas yang disusupkan pengarangnya secara mendadak di komik $P G S$, namun dikesankan telah dibebankan kepadanya sejak semula.

Menganalisis Panggilan untuk Bertualang dari Parmin akan sangat sulit jika hanya menyimak komik PGS. Sehingga komik Badjing Ireng (Djair, 1968) yang merupakan komik serial pertama Jaka Sembung perlu dijadikan rujukan. Tugas awal satu-satunya Jaka Sembung dari gurunya adalah bergabung dengan pendekar-pendekar di daerah Selatan, tetapi dalam PGS (Djair, 1969) muncul tugas tambahan lewat kilas balik agar dia juga mendaki puncak Ciremai, bahwa selain untuk menguji dirinya, akan ada satu hal yang sangat penting untuk ditemui langsung oleh Parmin, sesuatu yang tidak diketahuinya, tugas yang ternyata berkaitan dengan pola mitis hero dalam komik (gambar 2).

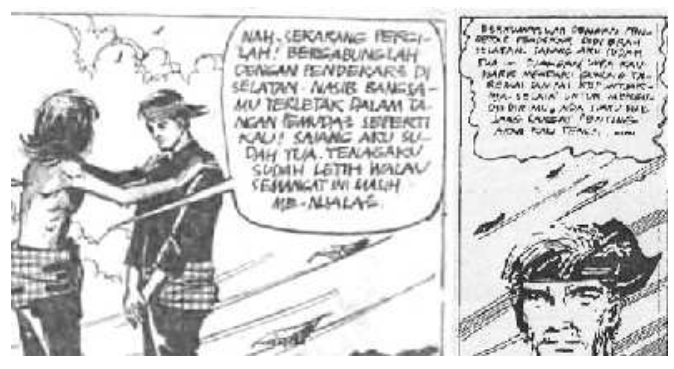

Gambar 2 Tugas awal untuk Parmin dan tugas tambahan dari gurunya Sumber: Djair, 1968 \& 1969

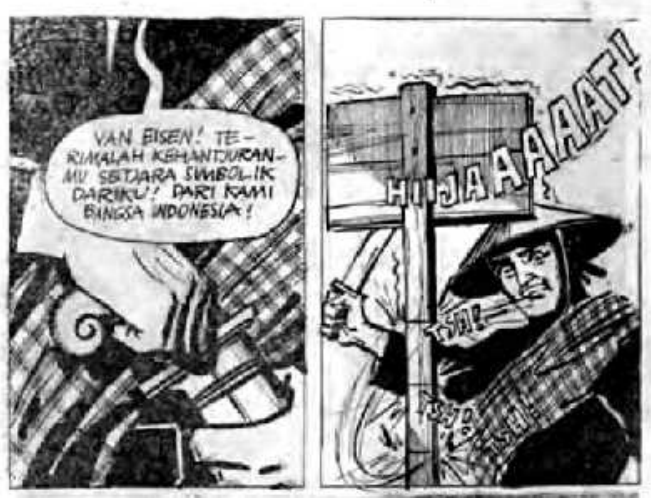

Gambar 3 Penyebutan "bangsa Indonesia" Sumber: Djair, 1968:31

Sambil memegangi pundak Parmin, gurunya mengatakan, "bergabunglah dengan pendekar-pendekar di Selatan. Nasib bangsamu terletak dalam tangan pemudapemuda seperti kau...”. Dengan mengetahui letak Pantai Eretan secara geografis, kini jelas sudah arah "Selatan" yang dimaksud, yaitu sebelah selatan dari Indramayu. Sementara kata "bangsa" merujuk pada [bangsa] Indonesia. Seperti bisa disimak saat Parmin menebas papan klaim kepemilikan tanah oleh Van Eisen, seorang tuan tanah di Kandanghaur, sembari berucap "terimalah kehancuran secara simbolik...dari kami bangsa Indonesia." (gambar 3). 
Tugas atau perintah gurunya untuk mengusir Belanda ini sangat terkait dengan historiografi nasionalisme Indonesia yang selalu menjadikan Belanda sebagai musuh bersama. Historiografi semacam ini mendasarkan kebutuhan untuk menyatukan kelompok masyarakat yang berbeda, sehingga nasionalismenya adalah antitesis terhadap kolonialisme Belanda. Perjuangan politik bangsa pada waktu itu memerlukan legitimasi atas nasionalisme sebagai suatu ideologi, sehingga anakronisme sejarah berlangsung (Purwanto,2006). Sehingga tidaklah mengherankan jika tokoh fiksi yang diceritakan hidup di masa VOC seperti Parmin sudah mempunyai gagasan tentang kebangsaan. Dijadikannya Belanda sebagai musuh juga berkaitan dengan dua hal: tujuan pragmatis untuk memikat pembaca, yaitu menanamkan jiwa nasionalis khas Masa Revolusi dan memenuhi harapan para penentang komik yang menginginkan agar komik memuat pesan moral, yang salah satunya adalah cinta tanah air.

Panggilan untuk Bertualang ini bersifat mitis mengingat tingginya risiko yang dihadapi Parmin. Kompeni yang digambarkan kejam, tamak, militeristik dan mempunyai senjata api menjadi krisis besar yang harus dihadapi Parmin yang hanya berbekal ilmu pencak silat dan senjata tradisional. Namun risiko ini sepadan dengan sejumlah pertolongan yang datang menghampirinya dan hanya akan datang kepadanya bila dia menjalankan kewajibannya sebagai seorang pendekar.

Dalam Monomyth, saat Panggilan diambil, maka komunitas yang ditinggalkan hero mitis lantas mengalami penyesuaian dan perluasan. Seperti itu pula komunitas anti penjajah dalam komik ini. Tugas tersebut sebenarnya mengandaikan adanya sekumpulan pendekar lain yang juga mempunyai tujuan dan pemikiran yang sama dengan Parmin: membebaskan Tanah Air dari belenggu penjajahan, dan kenyataan itulah yang ditemui Parmin. Dia menjalin pertemanan dan persaudaraan dengan para pendekar yang sejalan dengannya yang kelak membantunya melawan Belanda pada serial berikutnya.

Lingkup masyarakat yang semula hanya melibatkan gurunya seorang sebelum meninggalkan Pantai Eretan, meluas setelah dia dan rekan-rekan barunya, sesama pendekar, mengalahkan gerombolan perampok Lalawa Hideung yang menyerbu desa Kalimanggis. Di tengah-tengah mereka Parmin berkata: “...dan anda sekalian jangan lupa bahwa bangsa kita dalam penderitaan di bawah telapak kaki penjajah! Untuk itu mari kita bersatu lebih kokoh, karena kita menghadapi perjuangan yang lebih besar...suatu saat kita akan berkumpul kembali...mengusir penjajah dari bumi Nusantara!",

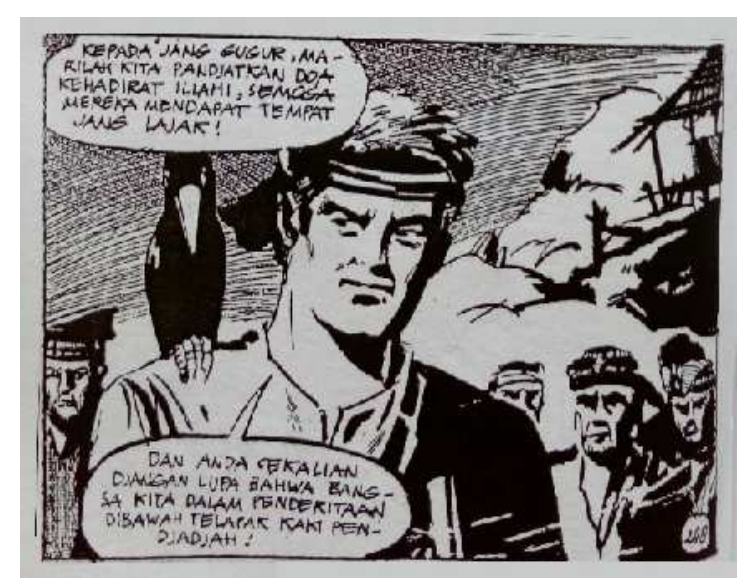

Gambar 4 Perluasan komunitas anti penjajah Sumber: Djair, 1969

Wajah Belanda sebagai penjajah memang tidak secara langsung berkonflik dengan Jaka Sembung dalam PGS. Kecuali kerap disebut sepintas lalu sebagai motivasi 
Keberangkatannya, Kompeni Belanda juga disebut sebagai penyebab diusirnya Sutawinata (ayah kandung Parmin) dari Kasultanan Cirebon, akibat pendapatnya untuk melawan Belanda bertentangan dengan keinginan Sultan Kanoman yang bermaksud menerima tawaran kerja sama dari Kompeni. Dari sini terlihat adanya komunitas anti penjajah Belanda yang bahkan merambah ke masa lalu di kala ayah kandung Parmin masih menjadi anggota Keraton.

Namun yang perlu diperhatikan, pihak Belanda dalam keseluruhan serial Jaka Sembung tidak selalu digambarkan jahat. Hal ini selain memperkaya dimensi tokoh-tokoh di dalamnya, turut menunjukkan bahwa yang dimusuhi oleh Jaka Sembung dan temantemannya bukanlah Belanda sebagai sebuah bangsa, melainkan pelaku kejahatan dan kesewenangan yang bisa dilakukan siapa saja. Dengan demikian Panggilan untuk Bertualang dari Parmin masih mengikuti struktur hero mitis. Hanya saja dia dihidupkan pada masa Kompeni yang sekali lagi dari segi sejarah Indonesia, terlanjur dijadikan musuh sesuai pandangan nasionalisme yang dominan pada tahun-tahun 1940-1960an.

\section{Penolakan atas Panggilan (Refusal of the Call)}

Penolakan atas Panggilan adalah tahapan di mana hero menolak menjawab tantangan atau mengambil tugas. Penolakan ini hampir selalu berakhir buruk bagi si hero atau calon hero (Campbell, 2004). Tetapi Penolakan atas Panggilan ini tidak pernah hadir dari petualangan Parmin dalam PGS. Tidak ada keraguan, keluhan, keinginan untuk berhenti bertualang, atau penolakan untuk melakukan petualangan itu. Setiap tugas diterima dan dikerjakannya, sehingga pembaca tidak akan pernah tahu konsekuensi buruk yang mungkin menimpa Parmin jika dia menolak panggilan tersebut.

Ketiadaan tahapan ini malah makin menegaskan adanya pola mitis dalam perjalanan Parmin. Ketiadaan Penolakan atas Panggilan menunjukkan ketaatan tingkat tinggi seorang pendekar terhadap tugas yang diamanahkan gurunya serta melogiskan apa yang menanti sesudahnya, yaitu mendapatkan limpahan dalam tahapan Bantuan Supranatural.

\section{Bantuan Supranatural (Supernatural Aid)}

Bantuan Supranatural akan diraih oleh hero yang menjawab panggilan tugas (Campbell, 2004:63). Parmin memperolehnya karena dia tidak menolak Panggilan untuk Bertualang, tidak pernah mengelak dari tugas, dan menerimanya dengan hati lapang. Perlindungan datang dari segenap penjuru dan dari satu bantuan tersebut dia beroleh bantuan lainnya, semacam rentetan mata rantai yang siap menolongnya.

Bantuan Supranatural dapat berwujud apa saja. Campbell (2004) secara spesifik mencontohkan Bantuan Supranatural berwujud orang tua yang menjadi pelindung dan mentor/pembimbing bagi hero, entah peri tua, kakek-kakek petapa, atau bahkan jin, yang membantu si hero keluar dari masalahnya dengan menyediakan si hero senjata pamungkas (jimat) untuk mengalahkan monster yang menanti si hero. Dua di antara Bantuan Supranatural yang akan dibahas adalah Begawan Sokalima dan tongkat besi berani. 


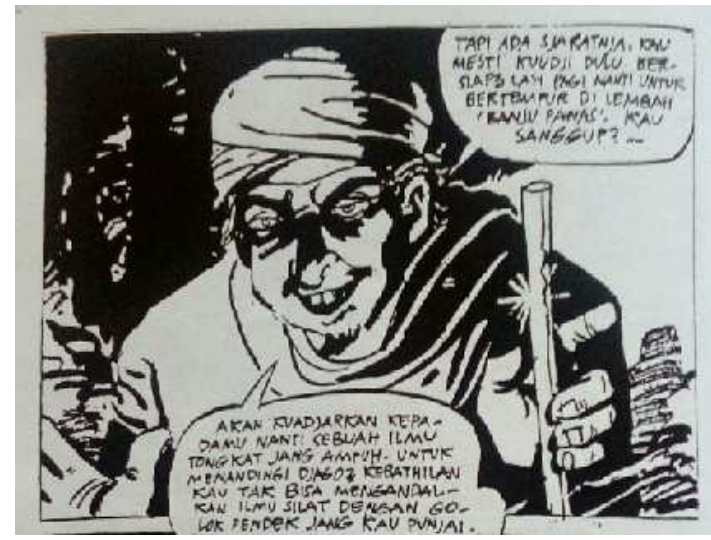

Gambar 5 Begawan Sokalima, mentor Jaka Sembung Sumber: Djair, 1969

Sang mentor bagi Parmin terangterangan menampakkan ciri mitisnya dan dilingkupi aura takdir. Secara kebetulan, di saat kritis, seorang laki-laki tua misterius bernama Begawan Sokalima menyelamatkan Parmin dari dinginnya halimun gunung Ciremai. Tubuhnya boleh jadi bungkuk dan buruk rupa, namun dia kuat, dan baik hati. Dia juga mengangkat Parmin menjadi murid setelah sempat menguji kelayakannya, mewariskan Ilmu Tongkat karena mengenali ilmu silat Gunung Sembung yang digunakan Jaka Sembung, dan menghadiahinya sebilah tongkat besi berani, dan merestui kepergian Parmin untuk melanjutkan perjalanan.

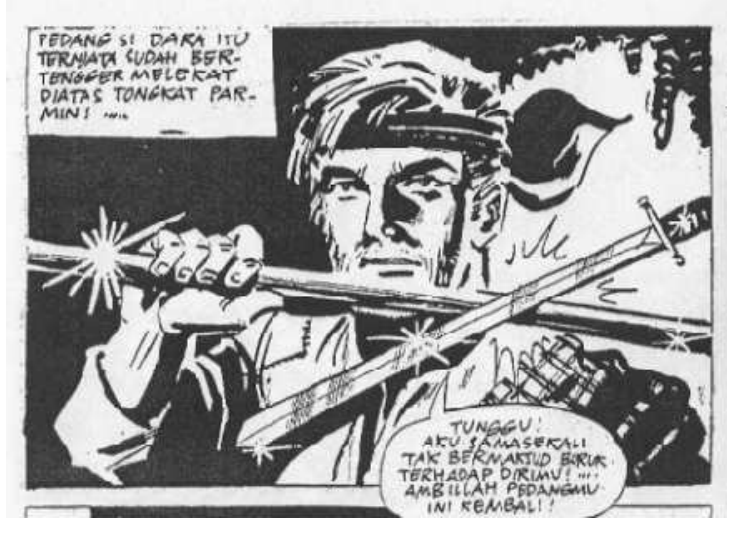

Gambar 6 Tongkat besi berani dari Begawan Sokalima

Sumber: Djair,1969

Tongkat besi berani pemberian Begawan Sokalima pada hakikatnya adalah tongkat ajaib.
Walaupun tidak mengandung ilmu sihir atau dirasuki makhluk gaib, tongkat ini mampu merenggut pedang dari tangan lawan. Penamaan Tongkat Besi Berani menyamarkan khasiat mitis dari pusaka tersebut. Tujuannya agar kekuatan tongkat ini bisa diterima nalar pembaca komik modern, bahwa karena terbuat dari besi berani/bermagnetlah tongkat ini dapat menarik logam. Kekuatan yang dimiliki hero dalam imajinasi populer kerap dibuat terlihat manusiawi dengan menjadikan semuanya itu sebagai gejala ekstrim dari anugerah alam (Eco, 2004:146). Hal ini disebabkan tantangan modern terhadap mitos berasal dari sains (Segal, 2004:11-12). Menurut sains, cara mitos menjelaskan dunia jelas tidak sesuai dengan pemahaman modern. Karenanya kredibilitas mitos diragukan oleh sains. Salah satu cara yang bisa dilakukan adalah menjadikan mitos sebagai sains modern, di mana sejumlah elemen yang bertentangan dengan sains modern direduksi atau diinterpretasi ulang sebagai fakta ilmiah. Tongkat besi berani adalah upaya pemasukakalan dari Djair yang menyertai medium komik modern sembari tetap membawa fungsi mitis senjata milik seorang hero.

\section{Melewati Ambang Pintu Pertama (The Crossing of The First Threshold)}

Dengan personifikasi takdirnya yang hadir lewat Bantuan Supranatural, Si Hero mitis memasuki sebuah dunia yang berbeda dari tempatnya berasal. Dunia di luar sana adalah dunia yang asing dan tidak dikenalinya, sebuah dunia yang mencerminkan bahaya. Mencoba melewatinya berarti mempertaruhkan nyawa. Saat melewati Ambang Pintu Pertama ini Si Hero akan bertemu penjaganya. 
Bentang alam yang akan menyambut seorang hero saat melewati Ambang Pintu tidak mudah. Ketahanan Si Hero akan diuji melalui serangkaian halangan (Campbell, 2004). Kisah PGS langsung menunjukkan ujian berat tersebut dengan membukanya dari pendakian Parmin di gunung Ciremai, yang jika mengikuti istilah "turun gunung," dia sebenarnya malah melakukan sebuah perjalanan terbalik, karena justru Parmin memulai perjalanan dari tepi pantai, masuk ke pedalaman, dan mendaki gunung. Penaklukan gunung bukanlah hal yang mudah bagi orang yang dibesarkan di pesisir seperti Parmin. Gunung mewakili apa yang menjadi lawan dari pantai: terjal dengan landai, batu-batuan tajam dengan butiran pasir. Parmin bersentuhan langsung dengan kutub kehidupan yang tidak pernah diketahuinya.

Belum terlalu jauh mendaki, dia sudah dihadang salah satu penjaga perbatasan dua "dunia" yang memisahkan moral hitam-putih kependekaran, yaitu seorang pendekar berjuluk Dewa Suci, musuh lamanya.

Karakteristik Dewa Suci berseberangan dengan Parmin. Dari segi fisik tubuhnya gempal dan botak. Dari segi moral dia pendendam, gila harta karena ingin mendapat uang hadiah penangkapan Bajing Ireng. Dari segi perangai, dia bukan saja arketipe penjahat tapi menjadi bagian dari sebuah krisis yang harus ditumpas seorang hero mitis. Jaka Sembung turut mengambil alih peran Tuhan untuk membinasakan makhlukNya lewat jurus yang namanya sangat ilahiah, Wahyu Taqwa. Dia selayaknya perpanjangan tangan Tuhan, atau Tuhan sendiri yang meminjamkan tanganNya kepada Parmin.

Lain lagi dengan seekor burung beo ajaib yang juga penjaga Ambang Dunia. Dalam perjalanannya menuruni gunung di daerah Kuningan, Parmin bertemu dengan seekor burung beo yang memintanya untuk membantu menjawab pertanyaan majikannya, seorang petapa yang meninggal bertahun lalu. Di hadapan kerangka Si Petapa di dalam rongga gua, terjadilah percakapan panjang, tentang apa itu agama, mengapa orang berperang karena agama, apa itu ibadah, apa hubungan kitab suci dengan nabi, dan bagaimana wujud Tuhan.

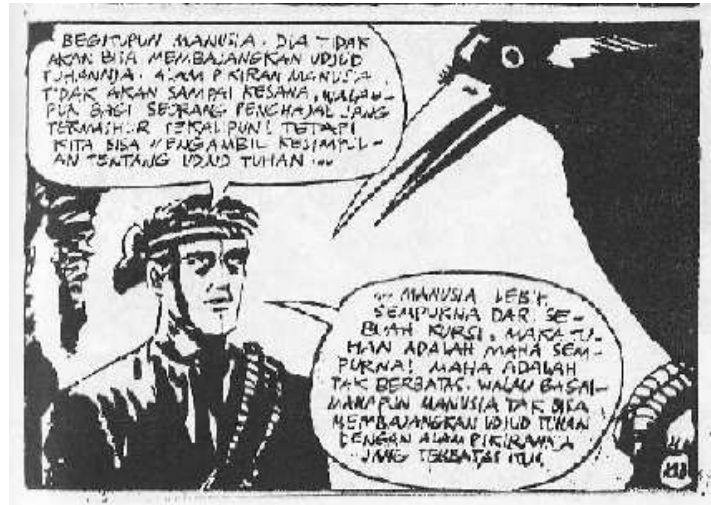

Gambar 7 Perbincangan Parmin dan Si Beo Sumber: Djair, 1969

Parmin berpendapat, agama adalah ajaran Tuhan untuk membimbing manusia ke jalan yang benar. Peperangan atas nama agama bukan disebabkan ajarannya tetapi karena nafsu bersaing pemeluknya. Ibadah adalah niat dan perbuatan bakti kepada Tuhan menurut yang diwajibkan agama agar manusia selalu mengingat Tuhan. Kitab suci adalah mukjizat bagi nabinya yang tidak dapat ditulis oleh pujangga manapun. Wujud Tuhan tidak akan dapat dibayangkan oleh makhluk ciptaanNya yang serba terbatas. Si Beo puas terhadap jawaban Parmin, mengabdikan diri kepadanya dan menolongnya dalam beberapa kali kesempatan. Dengan penundukan terhadap Si Beo, Parmin telah menguasai aspek spiritualitas yang diidealkan oleh masyarakat. Parmin 
bukan lagi sekedar manusia biasa. Dia menjadi penjaga dan perantara moralitas yang diidealkan tersebut

\section{Perut Ikan Paus (Belly of The Whale)}

Sukses melewati Ambang Pintu Si Hero bagaikan terlahir kembali yang secara simbolik disebut Perut Ikan Paus. Si Hero tidak menaklukkannya, melainkan membiarkan Ambang Pintu menelannya ke dalam lingkup wilayah yang tidak diketahui oleh Si Hero. Pada tahap ini dia akan tampak mati, tetapi sesungguhnya Si Hero bertransformasi menjadi pribadi yang lain, bersiap mengalami perubahan dalam hidupnya (Campbell, 2004).

Tahapan kritis dalam Keberangkatan di komik PGS terjadi kala Parmin terlambat menghindari halimun pekat yang menyelimuti lereng gunung. Gunung bukan tempat yang ramah bagi Parmin yang tumbuh besar di pantai yang berhawa panas. Ini adalah situasi di mana Parmin berada di antara dua dunia berbeda, antara hidup-mati, di dalam Perut Ikan Paus. Daya Ambang Pintu yang jauh lebih besar menelannya, dan tidak ada yang bisa dilakukan Parmin selain berpasrah, jatuh pingsan hingga Begawan Sokalima yang menyimbolkan Bantuan Supranatural menolongnya. Kebangkitan Parmin dari halimun mengajarkan kepadanya aspek manusia dan keilahiahan berjalan beriringan. Seorang pendekarpun demikian. Dia tetap memiliki aspek manusia dari seorang hero mitis yang bisa beralih dan berpindah antara dua dunia. Aspek manusia mengajarkan bahwa tidak selamanya si hero selalu tangguh, adakalanya dia terjatuh.

Lokasi munculnya halimun adalah tempat yang mulia karena letaknya lebih tinggi dari pantai. Tafsir semacam ini tidak akan sulit dipahami bagi masyarakat yang pernah mengenal kepercayaan bahwa gunung adalah tempat bersemayam para dewa atau bagaimana candi-candi punya analogi dengan gunung, dan pada kenyataannya dalam naratif $P G S$, Parmin memang beroleh kemuliaan di gunung ini tepat sesudah melewati halimun gunung. Sesuatu yang berkaitan dengan tugas untuk mendaki gunung yang diperintahkan gurunya. Tugas yang mengungkapkan jati dirinya sebagai seorang berdarah bangsawan. Kebangsawanan ini menunjukkan keistimewaannya dalam nalar hero mitis modern, bukannya dengan klaim bahwa dia dikirim oleh dewa/dewi atau turun ke dunia atau diceritakan sebagai inkarnasi dewa/dewi. Walau pada kisah komik berikutnya, kebangsawanan Parmin agaknya turut berperan atas peran kepemimpinannya menggelorakan perlawanan terhadap penjajahan Belanda.

\section{KESIMPULAN}

Dari pemaparan yang telah disampaikan, fase Keberangkatan Monomyth dari Parmin si Jaka Sembung dalam komik PGS, nyatanya memang ada. Sejalan pula ia dengan arketipe hero mitis yang sudah akrab bagi pembaca. Sesuatu yang idealnya diperbuat seorang hero: menolong sesamanya, membasmi kebatilan, sekaligus mempunyai kelemahan layaknya manusia biasa, menjadi panutan bagi manusia lainnya. Satu tahapan Keberangkatan dalam Monomyth memang tidak hadir, yaitu Penolakan atas Panggilan. Tetapi ketidakberadaannya justru makin menguatkan peran mitis Jaka Sembung. Selebihnya, fase-fase Keberangkatan hadir tidak saja dengan sejumlah penyesuaian yang bersifat lokal dan kontekstual, tapi karena $P G S$ adalah komik 
yang merupakan produk budaya populer masyarakat modern.

Panggilan untuk Bertualang Parmin adalah demi mengusir penjajah Belanda. Panggilan yang berawal sejak komik Jaka Sembung seri pertama ini memperlakukan penjajajah Belanda sebagai krisis karena kesewenangan mereka dan penindasan yang dilakukan, bukan Belanda selaku bangsa Eropa ataupun ras kulit putih. Ditetapkannya Belanda sebagai musuh sangat erat kaitannya dengan kondisi masyarakat Indonesia zaman 19401960-an. Ia adalah buah dari historiografi Indonesia yang memang menjadikan Belanda sebagai musuh demi menyatukan bangsa Indonesia yang baru merdeka.

Seperti pola hero mitis, ketika Panggilan diambil maka komunitas yang mendukung perlawanan terhadap Belanda pun turut meluas, bahkan dapat ditarik hingga ke masa lalu, saat ayah kandung Parmin masih menjadi penghuni Keraton. Bukan saja dari gurunya, maupun di kala Parmin mengumpulkan dukungan para pendekar di arah Selatan.

Sifat modern dari komik ikut memengaruhi bagaimana pola mitis disamarkan menjadi penuh penalaran dan keilmiahan. Bantuan Supranatural datang dalam wujud tongkat besi berani yang khasiatnya mampu merenggut pedang lawan. Ia bukanlah benda ajaib bertuah, melainkan karena tongkatnya mengandung medan magnet. Sesuatu yang hanya bisa diterima oleh masyarakat modern. Meski begitu salah satu Bantuan Supranatural masih dalam wujud mitisnya, Begawan Sokalima. Kehadirannya pun dilingkupi aura takdir. Seolah dunia sebegitu sempit, bahwa di saat kritis, ada seorang yang menyelamatkan nyawa Parmin dan mengangkatnya menjadi murid.
Ambang Pintu yang dilalui Parmin adalah pegunungan yang menguji kekuatan fisik Si Hero. Penjaganya, seorang pendekar jahat yang menguji moralitasnya melalui perbedaan perangai. Sementara Burung Beo ajaib hadir menguji kematangan spiritualitasnya sebagai pendekar.

Perut Ikan Paus adalah tahap di mana si hero tampak mati, yang darinya dia bertransformasi menjadi seseorang yang berbeda. Parmin mengalaminya di saat dia nyaris tewas karena halimun gunung Ciremai. Di mana sesudahnya dia bukan saja beroleh pengetahuan tentang bahaya halimun gunung, tapi juga anugerah ketika mengetahui asal usulnya yang tak lain keturunan bangsawan Keraton Cirebon.

Pola Keberangkatan Jaka Sembung dalam komik PGS memang masih mengikuti pola hero mitis. Keberangkatan yang nantinya menentukan tahapan Inisiasi dan Kepulangan Kembali. Kemodernan komik tidak lantas menghilangkan ikatan manusia terhadap mitologi kuno, bahwa hero mitis secara tidak disadari masih terus hadir dalam sendi kehidupan modern.

\section{DAFTAR PUSTAKA}

[1] Allison, Scott T., Goethals, George R., 2011, Heroes What They Do We Need, New York: Oxford University Press.

[2] Barker, Chris, 2013, Cultural Studies, Teori dan Praktik, penerjemah: Nurhadi, Yogyakarta: Kreasi Wacana.

[3] Bonneff, Marcel, 2008, Komik Indonesia, Jakarta: KPG

[4] Campbell, Joseph, 2004, The Hero With A Thousand Faces, New Jersey: Princeton University Press.

[5] Danesi, Marcel, 2002, Understanding Media Semiotic, London: Arnold Publisher. 
[6] Djair, 1968, Badjing Ireng, Bandung: Maranatha

[7] Djair, 1969, Pendekar Gunung Sembung, Bandung: PT Bintang Kejora.

[8] Eco, Umberto, 2004, The Myth of Superman, dalam, Arguing Comics, Literary Masters on Popular Medium, diedit oleh: Jeer Heet dan Kent Woncester, Jackson: University Press of Mississippi, hal. 146-164

[9] Kurnia, Anton, 2017, Buah Terlarang dan Cinta Morina, Yogyakarta: Basabasi.

[10] McCloud, Scott, 1993, Understanding Comics, New York: Harperperennial.

[11] Purwanto, Bambang, 2006, Gagalnya Historiografi Indonesiasentri?!, Yogyakarta: Ombak

[12] Rensma, Ritske, 2009, The Innateness of Myth, The New Interpretation of Joseph Campbell's Reception of C.G. Jung, London: Continuum International Publishing.

[13] Segal, Robert, 2004, Myth, A Very Short Introduction, New York: Oxford University

\section{KETERANGAN TAMBAHAN}

Tulisan merupakan laporan penelitian hibah yang diberikan dari Fakultas Arsitektur dan Desain UPN “Veteran” Jawa Timur 